\title{
Determinants of chronic pain among adults in urban area of Udupi, Karnataka, India
}

\author{
Paramjot Panda*, Navya Vyas, Sushma Marita Dsouza, Vamsi Krishna Boyanagari \\ Prasanna school of Public Health, Manipal Academy of Higher Education, Manipal, India
}

\section{A R T I C L E I N F O}

\section{Keywords:}

Chronic pain

Adults

Urban area

Risk factors

\begin{abstract}
A B S T R A C T
Background: Chronic pain is very common in Asian communities. It is a major cause of activity limitation and has a significant impact on individuals and society. One of the most common ailment for which patients seek for medical care is pain. This study was performed in the urban area to study the association of some of the modifiable risk factors of chronic pain.

Objective: To estimate the prevalence and associated risk factors of chronic pain among adults residing in the Urban area of Udupi Taluk in Karnataka, India.

Methods: The cross-sectional study included 360 participants of above 18 years of age. The participants were recruited using Simple Random Sampling technique from January 2017 to June 2017. Descriptive and analytical methods were used to estimate the prevalence and to identify the associated risk factors.

Results: It was observed during the study that prevalence of chronic pain for adults older than 18 years was $62 \%$. Low back pain and knee pain were the common ailments reported. About $50 \%$ of those who reported chronic pain, had the complaint for more than 5 years and reported more than six in Visual analogue scale. The postural factors associated with chronic pain were lifting weight, bend trunk heavily during work, repetitive movement of neck, trunk and shoulder, lifting hand above shoulder level and experience of fall.

Conclusion: Present research revealed that higher prevalence of chronic musculoskeletal pain exists in the urban population of Udupi Taluk, which was influenced by repetition of same joint movement, trauma and depression irrespective of the other risk variables.
\end{abstract}

\section{Introduction}

Morbidity is just a tip of the iceberg of the disease condition. Morbidity is defined as "any departure, subjective, or objective, from a state of physiological wellbeing"1 According to the World Health Organization (WHO), morbidity could be measured among some people who were ill, such as experience of illness and the duration of the disease. ${ }^{2}$ Although chronic pain does not have a high mortality rate and it is considered to be a disease of developed countries, now with more acceptance of sedentary lifestyle it contributes high rate of morbidity in developing countries. ${ }^{3}$ However, pain is a necessary function for preventing damage to the body. ${ }^{4}$ Individuals experiences acute, chronic, or intermittent pain or a combination of the three which has a significant impact on one's day to day life. ${ }^{1}$ In some cases, pain itself causes disability and it is one of the most common complaint for patient seeking medical care. ${ }^{5}$ WHO has recognized pain as a problem of global importance ${ }^{6}$ It is a silent epidemic which if not handled properly can affect the quality of life of an individual with chronic pain. It is the most prevalent cause of human suffering, worldwide, giving it the status of the fifth vital sign. ${ }^{7}$ Chronic pain is a prevalent problem in today's society with recent evidence suggestive of a persistent increase in the magnitude of the individuals with pain. The burden of chronic pain among adolescents is between $14 \%-24 \% .^{8}$ Chronic pain increases through the ageing process and various studies found that $61 \%$ of the elderly adults have chronic pain. ${ }^{9,10}$

Chronic pain has an impact on occupation, relationships, and daily life of people. ${ }^{11}$ Affective disorders such as anxiety, somatic dysfunction, depression, inability to work, disrupted social relationships and suicidal thoughts are termed as psychological distress (PD). ${ }^{12,13} \mathrm{PD}$ coexists with people living with chronic pain ${ }^{12}$ The standard of life is deteriorated by chronic pain, almost more than any other disease condition. In various studies, it was found that a person with chronic pain had a traumatic experience and had thoughts of suicide; $65 \%$ of the sufferer's report difficulty in sleeping and $49 \%$ suffer from

Abbreviations: WHO, World Health Organization; PD, psychological distress; PPS, probability proportionate to sampling; SPSS, statistical package for social sciences; n, number; CI, confidence interval; COPCORD, community oriented program for control of rheumatic disease; GHQ, general health questionnaire

* Corresponding author.

E-mail address: paramjot.panda@learner.manipal.edu (P. Panda). 
depression. Overall, 19\% of the individuals with chronic pain eventually lose their work. ${ }^{14}$ It is more common in women than men and becomes more common as age increases. ${ }^{13,8}$

In developing countries, due to lack of human resources, infrastructure and non-referral in the primary care settings, there is always a chance of under-reporting and misdiagnosis of musculoskeletal pain. In addition to this, there is negligence of factors related to pain like sleep, occupation and psychological manifestations. This study was done to estimate the burden and associated risk factors of chronic pain among adults residing in the Urban area of Udupi Taluk in Karnataka.

\section{Methodology}

\subsection{Study design, settings and eligibility criteria for selecting participants}

A community-based cross-sectional study was conducted among urban adult dwellers of Udupi Taluk in Udupi district of Karnataka, India. Self-report of pain which last for at least one week and within a month of conducting the study. Also, participants of age range from 18 to 60 years were recruited from January 2017 to June 2017.

\subsection{Data collection methods}

A semi-structured questionnaire was used for data collection. The tool was validated by the experts in the field for use of the tool. The questionnaire had three domains: Socio-demographic Characteristics, Chronic Pain Assessment, and Occupational Factors. The Psychological Distress among chronic pain individual was assessed by using General Health Questionnaire (GHQ-28), which is a standardized questionnaire used to assess the psychological distress. It contains 28 items from the original GHQ-28, across all dimensions and comprises domains such as Somatic Dysfunction, Anxiety, Social Dysfunction, and Depression which were used to collect the data. This was administered by the para medical professional and participants took 15-20 min to complete the questionnaire. The bus stop of the ward was considered as the starting point. If there was more than one lane then random selection was done using lottery method. Each household was considered as a study unit. The selection of the households differed from one ward to another i.e. occasionally the data collection started from the house on the lane or from the middle of the lane or in some instances from the first house of lane. This was done to minimise the selection bias.

The purpose of the study was explained to participants and asked first question 'How many adults aged 18 or older who live in your household experience pain from an illness or medical condition?' "terminate if zero" If responded Yes and agree, then the consent of the study subject was taken before the interview and asked General pain assessment and the psychological distress questionnaire. If the person had reported pain for six months or more, a structured questionnaire to assess the effect of chronic pain was administered.

\subsection{Sampling technique and sample size}

Single Stage Cluster sampling technique was used in the study by considering each ward of Udupi Taluk as a cluster. The list of wards (35 in number) which were procured from Udupi City Municipal Council was used as the sampling frame. A sample of each ward was obtained through Probability Proportionate to Sampling (PPS) to sample size. Using PPS technique, the total number of participants from each ward was selected. The study included participants of all proportion of specific age range from 18 to 60 till the desired sample size was obtained. Total 360 participants were included in the study. Prevalence $=0.30$ (Sarda k et al) ${ }^{10}$ using formula

$\mathrm{n}=\mathrm{Z}(1-\alpha / 2)^{2} \mathrm{P}(1-\mathrm{P}) / \mathrm{d}^{2}$

$\mathrm{Z}=\mathrm{Z}$ value (e.g. 1.96 for $95 \%$ confidence level), $\mathrm{p}=$ percentage picking a choice, expressed as decimal (0.5 used for sample size needed), $d=$ desired level of precision.

\subsection{Analysis}

The Statistical Package for Social Sciences (SPSS) version 15 for Windows was used to analyze the data. Through descriptive statistics, socio-demographics were expressed as frequencies and percentages. The multiple logistic regression analysis was done to find out the factors significantly associated with chronic pain. For ease of analysis, some of the variables having more categories were merged. The variables which were merged were as follows: Age, marital status, religion, the level of education, and the level of spouse education, multiple sites of pain and family income. All the variables were included to adjust for confounding. Odds ratio and $\mathrm{p}$-value $\leq 0.05$ were reported for the Multiple Logistic Regression.

\section{Results}

A total of 360 randomly selected adults have participated in the study. The number of participants was equal among males and females. Most of the study participants were Hindus (68.1\%), $81.4 \%$ were married, $35.8 \%$ had primary school education, and $55.3 \%$ of the study participants belonged to the annual income category of Rs 50000 to Rs100000. (Table 1). The prevalence of chronic pain among dwellers of Udupi Taluk was found to be $224(62.2 \%)$. Most of the male participants with chronic pain had moderate psychological distress 125 (56\%) and female had severe psychological distress 21 (52.5\%) as shown in (Table 2). The major two sites of pain reported by males were Knees (43.2\%) and Low Back (33.6\%), whereas females reported pain at the following sites such as Low Back (34.3\%), Wrist (29.3\%), and Knees (29.3\%)(Table 3). The lifestyle, socio-demographic and postural factors responsible for chronic pain were shown in (Table 4). The odds of getting chronic pain in the subjects in the age group 41-60 was 12.86 times $(95 \%$ CI $5.83,28.34)$ more than the subjects in the age group $18-40$ years, which was statistically significant $(p=0.001)$. The odds of getting constant pain in Hindus were found to be 21.48 times more when compared to Muslims, Christians and Jains, which was found to be statistically significant $(\mathrm{p}=0.033)$. Individuals who were married

Table 1

Socio-demographic characteristics of the study participants $(n=360)$.

\begin{tabular}{llll}
\hline Variables & Category & Frequency & Percentage \\
\hline \multirow{2}{*}{ Age Group (in years) } & $18-30$ & 74 & $\mathbf{2 0 . 6}$ \\
& $31-40$ & 92 & $\mathbf{2 5 . 6}$ \\
& $41-50$ & 80 & $\mathbf{2 2 . 2}$ \\
Gender & $51-60$ & 114 & $\mathbf{3 1 . 6}$ \\
& Male & 180 & $\mathbf{5 0}$ \\
Religion & Female & 180 & $\mathbf{5 0}$ \\
& Hindu & 245 & $\mathbf{6 8 . 1}$ \\
& Muslim & 59 & $\mathbf{1 6 . 4}$ \\
Marital status & Christian & 49 & $\mathbf{1 3 . 6}$ \\
& Jain & 7 & $\mathbf{1 . 9}$ \\
& Unmarried & 53 & $\mathbf{1 4 . 7}$ \\
Educational Level & Married & 293 & $\mathbf{8 1 . 4}$ \\
& Separated & 14 & $\mathbf{3 . 9}$ \\
& University Graduate & 54 & $\mathbf{1 5}$ \\
& Higher Secondary & 47 & $\mathbf{1 3 . 1}$ \\
& (11th-12th) & & \\
& High School (8th-10th) & 46 & $\mathbf{1 2 . 8}$ \\
& Primary school (1st-7th) & 129 & $\mathbf{3 5 . 8}$ \\
& No schooling & 84 & $\mathbf{2 3 . 3}$ \\
Annual Income (in & 50,000-1,00,000 & 199 & $\mathbf{5 5 . 3}$ \\
rupees) & 100,001-1,50,000 & 60 & $\mathbf{1 6 . 6}$ \\
& 1,50,001-2,00,000 & 67 & $\mathbf{1 8 . 6}$ \\
& 2,00,000-2,50,000 & 15 & $\mathbf{4 . 2}$ \\
& No income & 19 & $\mathbf{5 . 3}$ \\
\hline
\end{tabular}

$\mathrm{n}=$ Number. 
Table 2

Site of pain of study participants $(n=224)$.

\begin{tabular}{lcc}
\hline Main site of pain & $\begin{array}{l}\text { Men, Frequency (\%) } \\
(\mathrm{N}=125)\end{array}$ & $\begin{array}{l}\text { Women, Frequency (\%) } \mathrm{N}= \\
(99)\end{array}$ \\
\hline Neck pain & $12(9.6)$ & $13(13.1)$ \\
Upper back pain & $13(10.4)$ & $7(7.1)$ \\
Lower back pain & $42(33.6)$ & $34(34.3)$ \\
Shoulder pain & $26(20.8)$ & $15(15.2)$ \\
Elbow pain & $7(5.6)$ & $9(9.1)$ \\
Wrist pain & 0 & $29(29.3)$ \\
Hip pain & 0 & $9(9.1)$ \\
Knee pain & $54(43.2)$ & $29(29.3)$ \\
\hline
\end{tabular}

Table 3

Psychological distress among study participants $(n=224)$.

\begin{tabular}{lcccc}
\hline Gender & Mild & Moderate & Severe & Total \\
\hline MALE & $30(60)$ & $76(56.7)$ & $19(47.5)$ & $125(55.8)$ \\
FEMALE & $20(40)$ & $58(43.3)$ & $21(52.5)$ & $99(44.2)$ \\
Total & $50(100)$ & $134(100)$ & $40(100)$ & $224(100)$ \\
\hline
\end{tabular}

had $34.86(95 \%$ CI $2.71,102.34)$ times more chances of getting chronic pain when compared with participants who were unmarried found to be statistically significant $(\mathrm{p}=0.006)$. Persisting pain was $0.107(95 \% \mathrm{CI}$
$0.035,0.330$ ) times less in individual who had a primary education when compared with individuals with high school which was significant ( $\mathrm{p}=0.001$ ). The odds of having multiple sites of pain among study subjects was 2.1 times $(95 \%$ CI 1.01, 4.68) more than individuals with no or single site of pain. The odds of having chronic pain among individuals who lift weight continuously during work hours for more than 5 hours had $0.042(0.013,0.131)$ times less than the individuals who were not involved in lifting weight jobs and it was significant $(\mathrm{p}=0.012)$. Postural factors like lifting weight in a twisted position, bend heavily with trunk, repeated the movement with arm, elbow, fingers and trunk, reach hand during work, hold hand above shoulder level, work kneeled or squatted were significant ( $p=<0.005)$. The frequency of doctors' visits for individuals with persisting pain was eight $(95 \%$ CI $3.26,21.67)$ times more than participants with the irregular onset of pain and it was significant $(\mathrm{p}=0.001)$.

\section{Discussion}

This study was to estimate the burden and associated risk factors of chronic pain among adults residing in the Urban area of Udupi Taluk in Karnataka. Most of the studies are phone based not the population based and lack substantial information for the occurrence and associated risk factors of musculoskeletal disorders and its associated pain in India.

There were major strengths in this study. First it was population

Table 4

Multiple Logistic Regression Analysis of Factors related to Chronic Pain.

\begin{tabular}{|c|c|c|c|c|}
\hline \multirow[t]{2}{*}{ Variables } & \multirow[t]{2}{*}{ Category } & \multicolumn{2}{|c|}{ Chronic Pain } & \multirow[t]{2}{*}{ Odds ratio( $95 \% \mathrm{CI})$} \\
\hline & & $\begin{array}{l}\text { YES } \\
\text { Frequency (\%) }\end{array}$ & $\begin{array}{l}\text { NO } \\
\text { Frequency (\%) }\end{array}$ & \\
\hline \multirow[t]{2}{*}{ Age Group (Years) } & $18-40$ & $68(31.2)$ & $53(70.6)$ & 1 \\
\hline & $41-60$ & $154(68.8)$ & $40(29.4)$ & $12.86(5.83,28.34)$ \\
\hline \multirow[t]{2}{*}{ Gender } & Male & $125(55.8)$ & $55(40.4)$ & 1 \\
\hline & Female & $99(44.2)$ & $81(59.6)$ & $1.63(0.89,2.99)$ \\
\hline \multirow[t]{2}{*}{ Religion } & Non-Hindu & $69(30.80)$ & $46(33.8)$ & 1 \\
\hline & Hindus & $155(69.2)$ & $90(66.2)$ & $21.48(1.28,6.58)$ \\
\hline \multirow[t]{2}{*}{ Marital status } & UnMarried & $26(11.6)$ & 27(19.9) & 1 \\
\hline & Married & $198(88.4)$ & $100(73.5)$ & $34.86(2.71,102.34)$ \\
\hline \multirow[t]{3}{*}{ Level of Education } & University Graduate/high school & $59(26.3)$ & $42(30.9)$ & 1 \\
\hline & Primary school & $97(43.3)$ & $78(57.4)$ & $0.107(0.035,0.330)$ \\
\hline & No school & $68(30.4)$ & $16(11.8)$ & $0.190(0.043,0.833)$ \\
\hline \multirow[t]{4}{*}{ Family Income } & $10,000-15000$ & $52(23.2)$ & $15(11)$ & 1 \\
\hline & $>20,000$ & $7(3.1)$ & $8(5.9)$ & $0.070(0.008,0.610)$ \\
\hline & $5000-10000$ & $34(15.2)$ & $26(19.1)$ & $0.265(0.051,1.37)$ \\
\hline & No $/<5000$ & $131(58.5)$ & $87(64.0)$ & $0.580(0.115,2.91)$ \\
\hline \multirow[t]{2}{*}{ Multiple Sites of pain } & No & $101(74.3)$ & $130(58)$ & 1 \\
\hline & Yes & $35(25.71)$ & $94(42)$ & $2.1(1.01,4.68)$ \\
\hline \multirow[t]{2}{*}{ Lift weight in work } & No & $109(80.1)$ & $112(50)$ & 1 \\
\hline & Yes & 27(19.9) & $112(50)$ & $0.042(0.013,0.131)$ \\
\hline \multirow[t]{3}{*}{ Bend heavily with trunk } & No & $101(74.3)$ & $130(58)$ & 1 \\
\hline & Yes & $35(25.7)$ & $94(42)$ & $0.32(0.10,0.97)$ \\
\hline & Yes & $112(82.4)$ & $178(79.5)$ & $0.50(0.19,1.31)$ \\
\hline \multirow[t]{2}{*}{ Repeated movement with trunk } & No & $99(72.8)$ & $95(42.4)$ & 1 \\
\hline & Yes & $37(27.2)$ & $129(57.6)$ & $4.96(1.58,6.38)$ \\
\hline \multirow[t]{2}{*}{ Stretching hand during work } & No & $80(58.8)$ & $138(61.6)$ & 1 \\
\hline & Yes & $56(41.2)$ & $86(38.4)$ & $0.227(0.095,0.546)$ \\
\hline \multirow[t]{2}{*}{ Hold hand above shoulder level } & No & $116(85.3)$ & $155(69.2)$ & 1 \\
\hline & Yes & $20(14.7)$ & $69(30.8)$ & $4.21(1.32,13.40)$ \\
\hline \multirow[t]{2}{*}{ Work kneeled or squatted } & No & $131(96.3)$ & $214(95.5)$ & 1 \\
\hline & Yes & $5(3.7)$ & $10(4.5)$ & $0.002(0.01,0.065)$ \\
\hline \multirow[t]{2}{*}{ Experience fall } & No & $84(61.8)$ & $110(49.1)$ & 1 \\
\hline & Yes & $52(38.2)$ & $114(50.9)$ & $0.96(0.39,2.35)$ \\
\hline \multirow[t]{2}{*}{ Leave because of pain } & No & $79(58.1)$ & $123(54.9)$ & 1 \\
\hline & Yes & $57(41.9)$ & $101(45.1)$ & $2.19(0.76,6.30)$ \\
\hline \multirow[t]{2}{*}{ Visited doctor in last 6 months } & No & $69(50.7)$ & $63(28.1)$ & 1 \\
\hline & Yes & $67(49.3)$ & 161(71.9) & $8.41(3.26,21.67)$ \\
\hline \multirow[t]{2}{*}{ Pain being treated any way } & No & $95(69.9)$ & $142(63.4)$ & 1 \\
\hline & Yes & $41(30.1)$ & 82 & $0.72(0.276,1.90)$ \\
\hline
\end{tabular}

$\mathrm{CI}=$ Confidence Interval. 
based and target population was the general population which include participants from young, middle age, adults, working women, Teachers, police and drivers etc. Second this study used Probability Proportionate to Sample Size (PPS technique) which means all the eligible participants had chance to include in the study from all the wards of Udupi Taluk (Karnataka).

There were some limitations in this study. As this study is population based and include the participants who self-report of pain so could be a chance of recall bias. Second this study could not be able to focus on type of psychological distress.

Global prevalence rates of chronic pain (International Association of Study Pain criteria specifies at least six months) range from 11.5-55.2\% ${ }^{15}$, with a weighted mean prevalence of $35.5 \%$ across the nation. ${ }^{11}$ The present study reported the prevalence of chronic pain as $62.2 \%$ in general population. The prevalence of chronic pain was $30.2 \%$ in Hongkong ${ }^{13}$ and $74 \%$ in Srilanka. ${ }^{16}$ Chronic pain if left untreated, is associated with general physical, psychological, and psychological distress. Employment, daily activities, and measured dimensions of general health are increasingly and negatively affected by the presence of chronic pain. ${ }^{17}$

The present study reported moderate psychological distress among study subjects with chronic pain which was $60.1 \%$ and severe psychological distress was $17.3 \%$ in general population. Another study indicated that $30 \%$ subjects had the major depressive syndrome and $70.1 \%$ suicidal thoughts among individuals with chronic pain in a clinic in Tamil Nadu. These patients were dependent on medications and on care givers contributing to the development of behavioural patterns of general inactiveness. Thus, due to these inter-related factors, chronic pain patients were subjected to disabilities. ${ }^{8}$

In addition to the negative psychological and physiological effects, pain if not managed properly can impose a heavy economic burden. In adding to lost productive time, chronic pain increases healthcare utilisation owing to more regular primary care appointments and hospital admissions (a 2-fold increase) as well as emergency department visits (a 5 -fold increase), as compared to individuals without chronic pain. ${ }^{18}$ Although the high variation of chronic musculoskeletal pain is evident in different regions of the world, from the clinical chapters, it emerges clearly that the women subjects have higher odds of suffering from pain than men. ${ }^{19}$ Women in the present study also had higher risk of both moderate and severe pain than men, and it is not unexpected as advancing age, coupled with menopausal decrements of bone health exacerbates pain. In India, every third woman is osteoporotic and consequently, osteoporosis-related high fracture risk, and declining Bone Mineral Density (BMD) at forearm, neck and lumbar spine worsen the propensity of musculoskeletal pain. It has also been substantiated by other population-based cross-sectional studies that women often have more musculoskeletal pain problems than men. ${ }^{8,15}$

Epidemiological studies have derived the inverse relationship between socioeconomic status and musculoskeletal pain. British cohort study had reported that lowest social class had three-fold increased risk of widespread chronic pain in comparison to highest social class. ${ }^{20}$ Another study had reported that subjects living in less affluent areas have higher chances of widespread pain, physical disability, mental distress and low life satisfaction in comparison to subjects living in affluent areas. ${ }^{11}$ In a 15 month follow-up study, subjects belonging to moderate and less affluent areas were more likely to have widespread chronic pain. ${ }^{14}$ However, after adjusting the psychological factors in multivariate logistic regression, this impact was not evident suggesting that socioeconomic status which in many studies had been based upon home ownership, education level and employment status was not a risk predictor for musculoskeletal pain, unless residual confounding of other risk factors such as depression, anxiety and sleep quality are not adjusted appropriately. ${ }^{21}$ Comparable results had been observed in the present study in multiple logistic regression analysis socioeconomic statuses were observed to influence pain substantially when adjusted for the effects of other variables. It suggests that sedentary lifestyle was not an intransigent variable but influenced by other co-existing risk variables.

The effect of pain on PD and vice versa was not easy to understand because of their usual co-existence and bidirectional relationship. It has been observed that pain threshold was reduced in subjects having PD whereby somatic preoccupation may be the primary symptom. Almost 50 percent of the depressed patients suffering from depression report pain in their lifetime. In the primary care setting the complex coexistence of pain and PD is largely overlooked and most of the times, PD is considered as an artfact of musculoskeletal pain, which may lead to poor prognosis, misdiagnosis and under-treatment of existing pain. ${ }^{19}$

\section{Acknowledgements}

The authors would like to thank all the participants who participated in this study. We would like to show gratitude to the Manipal Academy of Higher Education, Manipal for their support. All contributors declare that there is no conflicts of interest and that there was no financial support for the study.

\section{References}

1. Kindig DA. Understanding population health terminology. Milbank $Q$ 2007;85(1):139-161.

2. Tuakli-Wosornu YA, Haig AJ. Implementing the World Report on Disability in West Africa: challenges and opportunities for Ghana. Am J Phys Med Rehabil. 2014;93(1 Suppl 1).

3. Woolf AD, Pfleger B. Burden of major musculoskeletal conditions. Bull World Health Organ. 2003;81(9):646-656.

4. Nakamura M, Nishiwaki Y, Ushida T, Toyama Y. Prevalence and characteristics of chronic musculoskeletal pain in Japan: a second survey of people with or without chronic pain. $J$ Orthop Sci. 2014;19(2):339-350.

5. Abdul Jalil N, Sulaiman Z, Awang MS, Omar M. Retrospective review of outcomes of a multimodal chronic pain service in a major teaching hospital: a preliminary experience in Universiti Sains Malaysia, Malaysian J Med Sci. 2009:16(4):55-65.

6. McAllister L, Wylie K, Davidson B, Marshall J. The World Report on Disability: an impetus to reconceptualize services for people with communication disability. Int $J$ Speech Lang Pathol. 2013;15(1).

7. Yeo SN, Tay KH. Pain prevalence in Singapore. Ann Acad Med Singapore. 2009;38(11):937-942.

8. Muthunarayanan L, Ramraj B, Russel J. Prevalence of prediabetes and its associated risk factors among rural adults in Tamil Nadu. Arch Med Heal Sci. 2015;3(2):178. Available from: http://www.amhsjournal.org/text.asp?2015/3/2/178/171899.

9. Gupta M, Kumar AS, Priyanka Das G. Depression-sleep disturbance-chronic pain syndrome Indian J Pain. 2014;28(3):177. Available from: http://www.indianjpain.org/text.asp? 2014/28/3/177/138456

10. Sarda K, Suryawanshi S, Chaturvedi S, Rao GP. Chronic pain and depression: an online survey on Indian experiences. Indian J Pain. 2014;28(3):166.

11. Yamada K, Matsudaira K, Imano H, Kitamura A, Iso H. Influence of work-related psychosocial factors on the prevalence of chronic pain and quality of life in patients with chronic pain. BMJ Open. 2016;6(4):e010356.

12. Davidson B, Hill AE, Nelson A. Responding to the World Report on disability in Australia: lessons from collaboration in an urban Aboriginal and Torres Strait Islander School. Int $J$ Speech Lang Pathol. 2013;15(1).

13. Man AKY, Chu MC, Chen PP, Ma M, Gin T. Clinical experience with a chronic pain man agement programme in Hong Kong Chinese patients. Hong Kong Med $J$ 2007;13(5):372-378.

14. Macfarlane GJ, Norrie G, Atherton K, Power C, Jones GT. The influence of socioeconomic status on the reporting of regional and widespread musculoskeletal pain: results from the 1958 British Birth Cohort Study. Ann Rheum Dis. 2009;68(September (10)):1591-1595. Available from: http://ard.bmj.com/content/68/10/1591.abstract.

15. ÉBM Vieira, Garcia JBS, Silva AAM. Chronic pain, associated factors, and impact on daily life: are there differences between the sexes? Cad Saú. 2012;28(8):1459-1467. Available from: http://www.scielosp.org/scielo.php?script = sci_arttext\&pid $=$ S0102-

$311 \mathrm{X} 2012000800005 \& \operatorname{lng}=$ en\&nrm = iso\&tlng = en\%5Cnpapers $3: / /$ publication/doi $/ 10$ 1590/s0102-311x2012000800005.

16. Merskey H, Bogduk N. Classification of chronic pain. IASP Pain Terminol. 1994240 p.

17. Peiris-John RJ, Attanayake S, Daskon L, Wickremasinghe AR, Ameratunga S. Disability studies in Sri Lanka: priorities for action. Disabil Rehabil. 2013;36(20).

18. Yang S-Y, McCracken LM, Moss-Morris R. Psychological treatments for chronic pain in east and southeast asia: a systematic review. Int J Behav Med. 2015(March). Available from: http://www.ncbi.nlm.nih.gov/pubmed/25814461.

19. Dhillon H, Khullar S, Kaur G, Sharma R, Mehta K, Walia JPS, et al. Prevalence and predictors of chronic musculoskeletal pain in the population of Punjab. Int $J$ Health Sci Res. 2016;6(December):248-258.

20. Ferreira dos KS, Speciali JG. Epidemiology of chronic pain in the office of a pain specialist neurologist. Arq Neuropsiquiatr [Internet]. 2015;73(7):582-585. Available from: http:// www.scielo.br/scielo.php?script = sci_arttext\&pid = S0004-282\%C3\%972015000700582\& $\operatorname{lng}=$ en\&nrm $=$ iso\&tlng $=$ en

21. Davies KA, Macfarlane GJ, McBeth J, Morriss R, Dickens C. Insecure attachment style is associated with chronic widespread pain. Pain [Internet]. 2009;143(June (3-24)):200-205. Available from: http://www.ncbi.nlm.nih.gov/pmc/articles/PMC2806947/. 